\title{
Prevalence and Risk Factors of Asthma in Children Aged 13-14 Years
}

\author{
Ina Rosalina, Cissy B Kartasasmita, Myrna Soepriadi \\ (Department of Child Health, Faculty of Medicine, University of \\ Padjadjaran/Hasan Sadikin, Bandung)
}

\begin{abstract}
To determine the asthma prevalence and the role of some risk factors of asthma in children aged 13-14 years in Bandung, a study was conducted from April to May 1996 using the International Study of Asthma and Allergies in Childhood (ISAAC) written questionnaire. The study was conducted in 12 junior high schools (SMP), selected by multistage population random sampling from 6 district in the municipality of Bandung. A total of 3118 questionnaires were collected. The cumulative prevalence of asthma was $6.4 \%$ and the 12 month prevalence was $2.6 \%$. The prevalence was higher in male, with a ratio of male : female of 1.48:1. The prevalence of asthma increased significantly in children with history of atopy in the family (OR 6.1; $<<0.01$ ); however no significant differences was found between children with one or both parents having history of atopy. The prevalence of asthma in smoking children, matemal and room mates had also increased significantly $(O R=2.1 ; 2.3 ; 2.6$ and $p=<0.05 ;<0.01 ;<0.01$ respectively). However there was no significant effect of paternal smoking $(p=0.074)$. The use of mosquito spray in the bedroom and having pets showed no effect on the prevalence of asthma ( $p=0.86$ and 0.56 respectively). [Paediatr Indones 1998; 38:265-272]
\end{abstract}

\section{Introduction}

The infection rate is declining due to success of immunization and the use of antibiotics; consequently, non-infective diseases such as asthma grow and become a community health problem. In the last decade a lot of reports comug from developed countries stated that the prevalence and degree of asthma was increasing. Knowing

Author's address: Ina Rosalina, Department of Child Health, Medical Schont, Padjadjaran Universily, Jalan Pasir Kaliki.

Bandung, Indonesia 
the asthmatic prevalence and the role of risk factors influencing the manifestations of asthma is very important in order to give a better cure to the disease.

Using ISAAC' (International Sturly of Asthma and Allergies in Childhood) questionnaires, the asthmatic prevalence in children aged 13-14 years was observed. Children of this age is known as adolescents, changing from childhood to maturity. There are certain physical and psychological changes correlate to asthmatic problems in adolescence, such as the smoking habit that is a major risk of asthmatic development $/$ In this study effects of cigarette smoke was correlated with the incidence of asthma and also usage of mosquito spray and pets at home.

\section{Methods}

This was a cross sectional study using questionnaires. Schools were selected by a multistage population random sampling. From 6 districts in the municipality of Banclung, 2 kecamatans (subdistricts) was chosen randomly. In each kecamatan one junior high school was also chosen randomly, so that 12 schools were selected. All students aged between 13 to 14 years were inclucled in the study to fill in the questionnaires.

Data collected from the completely filled questionnaires were processed using computer program SPSS 7.0. Data of the prevalence and degree of severity of asthma were clescribed and influence of risk factors for asthma and risk ratio between at risk group to without risk group were analyzed using odds ratio. Chi-square test was applied and $95 \%$ confidence intervals were provided.

\section{Results and Discussion}

From 12 junior high schools, 3200 questionnaires were collected; of them 3118 $(97.4 \%)$ were completely filled and served as the base for analysis. The characteristics of the study subjects were listed in 'able 1.'

\section{Asthma. prevalence and degree of severity}

Our data show that asthmatic cumulative prevalence in children aged 13-14 years in Bandung was $6.4 \%$, and asthmatic period prevalence for one year before in this children was $2.6 \%$. This data show a decline of asthmatic incidence in puberty. It is usually believed that in puberty, asthma has a better outgrow, due to better prevention and therapy, also by nature. Report of asthmatic prevalence in Singapore done by Goh et al $]^{2}$ using the same age group and study methods also showed the same declination (cumulative prevalence $18.6 \%$ and period prevalence $9.9 \%$. The prevalence of asthma 
Table 1. Study subject characteristics

\begin{tabular}{lcc}
\hline Characteristics & No. of subjects & Percentage \\
\hline Age: 13 years & 1676 & $53.8 \%$ \\
14 years & 1442 & $46.2 \%$ \\
Sex: Male & 1631 & $52.3 \%$ \\
$\quad$ Female & 1487 & $47.7 \%$ \\
History of atopy: & & \\
Positive & 755 & $24.2 \%$ \\
Negative & 2363 & $75.8 \%$ \\
\hline
\end{tabular}

in Singapore was much higher than in Bandung. According to Lau, asthmatic prevalence in developed countries in the last decade has been growing; this was probably due to change in living habits, spending $95 \%$ or more of the time indoors, closely contact with indoor allergens such as mites, pets allergens and other allergens. ${ }^{3}$

Severe asthma is characterized by frequent attack, presence of nocturnal attack, and speech difficulty. In this study most asthmatic children had a rare attack (1-3 times/year), $12.2 \%$ had 4-12 attack/year, and only $3.7 \%$ had more than 12 attack/year. Most subjects never complained about nocturnal attack, only $18.3 \%$ with no more than once a week and $15.8 \%$ with more than once a week; $53.7 \%$ complained about speech difficulties during attack.

\section{Sex distribution}

The sex distribution of children with asthma shows that asthma in male subjects was 1.5 times higher than in female (Table 2)

Table 2. Sex distribution of children with asthma

\begin{tabular}{lccccc}
\hline & \multicolumn{2}{c}{ Male } & \multicolumn{2}{c}{ Female } & \multirow{2}{*}{ M:F Ratio } \\
\cline { 1 - 5 } & $n$ & $\%$ & $\mathrm{n}$ & $\%$ & \\
\hline History of attack & 117 & 59.1 & 81 & 40.9 & $1.44: 1$ \\
Asthma in the year before & 49 & 59.8 & 33 & 40.2 & $1.48: 1$ \\
\hline
\end{tabular}


Various reports showed that asthma prevalence in male was about 1.5 to 2 times higher than in female. ${ }^{4 \cdot(6)}$ No explanation about this is available.

\section{Family history of atopy}

Table 3 depicts the relation between history of atopy in first degree relatives and the occurrence of asthmatic attack

Table 3. Asthma attack in one year before

\begin{tabular}{lcccccc}
\cline { 3 - 6 } & & Yes & No & p & OR & $95 \% \mathrm{Cl}$ \\
\hline Family atopy & Yes & $53 / 7.0 \%$ & $702 / 93 \%$ & $<0,01$ & 6.1 & $3.8 ; 9.6$ \\
& No & $29 / 1.2 \%$ & $2.334 / 98.8 \%$ & & & \\
$\begin{array}{l}\text { Parental } \\
\text { atopy }\end{array}$ & One & $35 / 7.2 \%$ & $451 / 92.8 \%$ & 0.567 & 1.2 & $0.64 ; 2.24$ \\
& & & & & & \\
\hline
\end{tabular}

$\mathrm{OR}=$ odds ratio $; 95 \% \mathrm{Cl}=95 \%$ confidence intervals

This table shows that the prevalence of asthma in the preceding year in children aged 13-14 years was influenced by the presence of atopy. Risk to asthma was six times higher in group with positive familial atopy compared with group without familjal atopy history; the difference was statistically significant $(\mathrm{p}<0.01)$. Although familial atopy history showed relationship with asthma, there was no significant difference between single or both parents atopy. This result was different with studies done by Coultas and Slamet ${ }^{5}$ and Shapiro, ${ }^{7}$ that showed that the prevalence of asthma in both parents atopy was higher than that in single parent.

\section{Pollution of cigarette smoke}

Cigarette smoke was a major air pollutant. According to Meltzer ${ }^{B}$ cigarette smoke contains chemicals like nicotine, tar, and carbon monoxide that could be hazardous to the respiratory epithelium. Smoking has a close relationship with asthma and other upper respiratory tract diseases. Several studies reported elevated $\operatorname{IgE}$ and positive skin test to environmental allergens to smoking people. ${ }^{3}$ Constant contact with smoking influenced the FEV, (forced expiratory volume in one second). The effect of cigarette smoke was not only to active smoker, but also to children with smoking parents (passive smokers). 
Table 4 shows that the prevalence of asthma in smoking children was $5.1 \%$, whereas in non smoking children the prevalence was $2.1 \%$. Smoking mothers significantly influence to the prevalence of asthma ( $p<0.01$; OR 2.3). Gortmaker ${ }^{10}$ reported elevated asthma prevalence in children up to 17 years old from $5.0 \%$ to $7.7 \%$ in smoking mothers. Charlton also reported positive correlation in smoking mothers to not smoking 8-19 years old children in Britain." No positive association was found between smoking fathers to asthma prevalence in this study. They could be smoking else where not close to their children. Further studies are necessary to confirm this findings. Smoking room-mates significantly associated with asthma $(p=0.006 ; \quad O R=$ 2.6). Passive smoking due to room-mates should get a better attention.

Table 4. Influence of smoking to the prevalence of asthma

\begin{tabular}{|c|c|c|c|c|c|c|c|}
\hline \multicolumn{8}{|c|}{ Asthma in one year } \\
\hline & \multicolumn{2}{|c|}{ Yes } & \multicolumn{2}{|c|}{ No } & \multirow[t]{2}{*}{$p$} & \multirow[t]{2}{*}{ OR } & \multirow[t]{2}{*}{$95 \% \mathrm{Cl}$} \\
\hline & $n$ & $\%$ & $n$ & $\%$ & & & \\
\hline \multicolumn{8}{|l|}{ Study subject } \\
\hline a Smoking & 9 & 5.1 & 168 & 94.9 & 0.04 & 2.1 & $1.0 ; 4.3$ \\
\hline - Not smoking & 73 & 2.5 & 2868 & 97.5 & & & \\
\hline \multicolumn{8}{|l|}{ Father } \\
\hline - Smoking & 53 & 2.3 & 2231 & 97.7 & 0.07 & 0.7 & $0.4 ; 1.0$ \\
\hline - Not smoking & 29 & 3.4 & 805 & 96.6 & & & \\
\hline \multicolumn{8}{|l|}{ Mother } \\
\hline - Smoking & 13 & 5.3 & 230 & 94.7 & 0.006 & 2.3 & $1.3 ; 4.2$ \\
\hline - Not/smoking & 69 & 2.4 & 2806 & 97.6 & & & \\
\hline \multicolumn{8}{|l|}{ Roommates } \\
\hline - Smoking & 9 & 6.2 & 137 & 93.8 & 0.01 & 2.6 & $1.3 ; 5.3$ \\
\hline - Not smoking & 73 & 2.5 & 2899 & 7.5 & & & \\
\hline
\end{tabular}

Note: $\mathrm{OR}=$ odds ratio; $95 \% \mathrm{Cl}=95 \%$ confidence intervals 


\section{Mosquito spray}

Mosquito spray was an irritant inhalant that could cause bronchial hyper-responsiveness. This spray is commonly used inhalant in, but how far it influence asthma is still unknown. Table 5 shows no difference between groups using and not using mosquito sprays. No information were collected on the duration of mosquito spray, type of rooms, type of mosquito spray etc.

Table 5. Asscciation between prevalence of asthma and the use of mosquito spray

\begin{tabular}{|c|c|c|c|c|c|c|}
\hline & \multicolumn{6}{|c|}{ Asthma in last one year } \\
\hline & \multicolumn{2}{|c|}{ Yes } & \multicolumn{2}{|c|}{ No } & \multicolumn{2}{|c|}{ Total } \\
\hline & $n$ & $\%$ & $n$ & $\%$ & $n$ & $\%$ \\
\hline \multicolumn{7}{|c|}{ Use of mosquito spray } \\
\hline - Yes & 51 & 2.7 & 1858 & 97.3 & 1909 & 100.0 \\
\hline - No & 31 & 2.6 & 1178 & 97.4 & 1209 & 100.0 \\
\hline Total & 82 & 2.6 & 3036 & 97.4 & 3118 & 100.0 \\
\hline
\end{tabular}

$$
x^{2}=0.033 ; d f=1 ; p=0.855
$$

\section{Home pets}

Home pets, especially cats and dogs could be an important allergen to asthma. Dreborg $^{11}$ reported that fur, saliva, and stools are inhalant allergens. The duration of contact and allergen concentration was the major factor in the role of allergen to asthma. ${ }^{12}$

In Table 6 no significant association was seen in asthmatic prevalence between children who had pet at home and who had not. Munir ${ }^{13}$ reported that home pet allergen was found in high concentration in public facilities such as school, though pets were forbidden there. Pets allergen concentration was even higher at school than in asthmatic children's home. Therefore, although no significant asthmatic prevalence difference was found in children having or having no pets at home, to determine the role of pets allergen as a risk factor in precipitating asthma, certain tests should be done, such as: skin sensitivity test and E specific immunoglobulin titer to pets allergen, especially dogs and cats. (In Sweden 70\% asthmatic children were found sensitive to cats and dog allergen). 
In conclusion, we have found that the cumulative and period prevalence of asthma in children aged 13-14 years in Bandung were $6.4 \%$ and $2.6 \%$, respectively, with male to female ratio of $1.48: 1$. Most asthmatic children had rare attack (1-3 per year) with asthma prevalence was significantly no nocturnal attack. The most frequent complain was speech difficulty during attacks. The prevalence of asthma was associated significantly with history of atopy, smoking (active and passive), but was not associated with and use of mosquito spray or pet.

Table 6. Association between asthma prevalence and home pets

\begin{tabular}{crrrrrr} 
& \multicolumn{7}{c}{ Asthma during the last one year } \\
\cline { 2 - 8 } & \multicolumn{2}{c}{ Yes } & \multicolumn{1}{c}{ No } & \multicolumn{2}{c}{ Total } \\
\hline Pets at home & 23 & 2.3 & 982 & 97.7 & 1005 & 100.0 \\
Cats & 12 & 3.0 & 387 & 97.0 & 399 & 100.0 \\
Birds & 5 & 2.0 & 241 & 98.0 & 246 & 100.0 \\
Chickens & 3 & 1.9 & 154 & 98.1 & 157 & 100.0 \\
Dogs & 1 & 0.7 & 138 & 99.3 & 139 & 100.0 \\
Others & 2 & 3.1 & 62 & 96.9 & 64 & 100.0 \\
\hline No pets & 59 & 2.7 & 2054 & 97.3 & 2113 & 100.0 \\
\hline Total & 82 & 2.6 & 3036 & 97.4 & 3118 & 100.0 \\
\hline
\end{tabular}

$x^{2}=3.833 ; p=0.566$

\section{References}

1. Gortmaker SL, Walker DK, Jacob FH et al. Parental smoking and the risk of childhood asthma. Am J Public Health 1982;72: 574-9.

2. Goh DYT, Chew FT, Quek SC et al. Prevalence and severity of asthma, rhinitis and eczema in Singapore school children. Arc Dis Child 1996;74: 131-5.

3. Lau S. Exposure to indoor inhalant allergens. Pediatr Allergy Immunol 1996;9: 108-10.

4. Godfrey S. Childhood asthma. In: Clark TJH and Godfrey S, ed. Asthma. 2nd ed. London: Chapman and Hall 1983;415-52.

5. Coultas DB, Slamet JM. Epidemiology and natural history of childhood asthma. In: Tinkelman DG et al, ed. Childhood asthma pathophysiology and treatment. New York. Marcel Dekker Inc 1987;131-52. 
6. Sears RM. Epidemiological trends in bronchial asthma. In: Tinkelman DG et al ed. Asthma in pathophisiology and treatment. New York: Marcel Dekker Inc 1991: 1-37.

7. Shapiro GG. Childhood asthma: Update. Pediatric in Rev. 1992;13: 403-12.

8. Meltzer EO. Non pharmacologic approaches to the management of asthma in childhood. In: Tinkelman DG et al ed. Childhood asthma, pathophysiology and treatment. Marcel Dekker Inc 1987;282-6.

9. Dahms TE, Bolin JF, Slavin RG. Passive smoking. Chest 1981;80: 530-4.

10. Charlton A. Children's coughs related to maternal smoking. Br Med J 1984;288: 1647-9.

11. Dreborg S. Allergen levels causing sensitisation, bronchial hyper-reactivity and asthma. Pediatr Allergy Immunol 1995; 7: 22-6.

12. Wahn U, Lau S. Strategies for indoor allergen elimination. Pediatr Allergy Immunol 1995;6: 42-6.

13. Munir AKM. Environmental factors influencing the levels of indoor allergens. Pediatr Allergy Immunol 1995;6: 13-21. 